\title{
O PAEG e o Plano Trienal: Uma Análise Comparativa de suas Políticas de Estabilização de Curto Prazo *
}

\author{
Eduardo F. Bastian \\ Professor - Universidade Federal do Rio de Janeiro (UFRJ) \\ Endereço para contato: Av. Pasteur, 250 - sala 103, Urca - Rio de Janeiro -RJ \\ CEP: 22290-240 - E-mail: eduardobastian@ie.ufrj.br
}

Recebido em 31de janeiro de 2012. Aceito em 14 de agosto de 2012.

\begin{abstract}
Resumo
O presente artigo tem por objetivo analisar as políticas de estabilização de curto prazo propostas pelo Plano Trienal (1962) e pelo Programa de Ação Econômica do Governo (1964) através da comparação das principais medidas implementadas e dos resultados alcançados pelos dois planos. No caso, pretende-se mostrar que os planos tinham semelhanças, sendo a política salarial do PAEG o principal ponto de distinção. Nesse contexto, as grandes diferenças de desempenho foram devidas à incapacidade do Trienal - em função dos turbulentos contextos interno e externo - de equacionar os problemas do conflito distributivo e do estrangulamento externo. O PAEG, por sua vez, equacionou os dois problemas, mas resolveu o conflito distributivo através de uma solução regressiva e, no caso do estrangulamento externo, obteve uma ajuda norte-americana com a qual o Plano Trienal não pôde contar.
\end{abstract}

\section{Palavras-Chave}

políticas de estabilização, Plano Trienal, PAEG

\begin{abstract}
This work discusses the short term stabilisation policies implemented by two plans Three-Year Plan (Trienal) of 1962) and the Government's Economic Action Programme (PAEG) of 1964 - in order to compare their main measures and results. It is intended to show that these plans had similarities being PAEG's wage policy the main point of difference. In this context, their performance differences were due to the turbulent internal and external contexts that the Three-Year Plan faced and that left it unable to solve the problems related to the distributive conflict and the external constraint. The Government's Economic Action Plan solved these problems, but the solution employed in terms of the conflicting claims was a regressive one and the external constraint was overcome with a help of US authorities that was not offered to the Three-Year Plan.
\end{abstract}

- Agradeço a Almir Pita, Carlos Pinkusfeld Bastos, Fabio Sá Earp e Franklin Serrano por comentários e sugestões a versões anteriores do artigo, e a Maurício Metri, Ralph Zerkowski e Ricardo Bielschowsky pelas discussões sobre o tema deste trabalho. Agradeço ainda aos pareceristas anônimos da revista por seus comentários. Os eventuais erros e omissões remanescentes são de minha responsabilidade. 


\section{Keywords}

stabilisation policies, Three-Year Plan; PAEG

\section{JEL Classification}

N16

\section{Introdução}

Os primeiros anos da década de 1960 foram, no Brasil, um período de grande turbulência nos campos político e econômico. $\mathrm{Na}$ política, o país viveu, entre outras coisas, a renúncia de um presidente e um golpe militar que instaurou uma ditadura que duraria duas décadas. Quanto à economia, por sua vez, o período foi marcado por uma forte elevação nas taxas de inflação, queda das taxas de crescimento e dificuldades no balanço de pagamentos.

Nesse contexto de crise houve, na primeira metade da década, duas importantes tentativas de eliminar as pressões inflacionárias e recolocar o país no caminho do crescimento econômico: o Plano Trienal (dezembro de 1962) e o Plano de Ação Econômica do Governo (novembro de 1964). Apesar da proximidade das datas entre estes planos, os dois foram, todavia, formulados em contextos políticos muito diversos. O Trienal surgiu durante o governo democrático e de esquerda de João Goulart, enquanto o Plano de Ação Econômica do Governo (PAEG) foi formulado no âmbito de uma ditadura de orientação conservadora. No caso, esta diferença de contexto ocorreu porque o Trienal foi o último plano do governo de Goulart antes de sua deposição, enquanto que o PAEG foi o primeiro plano do regime militar implantado após o golpe de abril de 1964.

Outra importante diferença reside nos resultados alcançados pelos dois planos. O Trienal fracassou no seu intento de estabilizar a economia e já em seu primeiro ano a taxa de crescimento ficou em 0,6\% - contra uma previsão de 7\% - e a inflação subiu para quase $80 \%$ no Índice Geral de Preços (IGP) dezembro a dezembro, enquanto a expectativa era de que a inflação declinasse. O PAEG, por outro lado, se não foi capaz de atingir as metas de inflação planejadas, obteve resultados muito melhores do que o Trienal. No caso, o plano conseguiu controlar o processo inflacionário (inflação média de 45,5\% no período $1964-67$ e de $25 \%$ em 1967), bem como retomar o cres- 
cimento econômico, ainda que a taxas bem mais modestas $(4,2 \%$ ao ano no período 1964-67) do que as registradas durante o governo de Juscelino Kubitschek (1956-61) (Hermann, 2005, p. 79). Ademais, há uma opinião praticamente generalizada que o PAEG criou as condições internas para que o país experimentasse aquilo que se convencionou chamar de milagre econômico (1968-1973).

Ocorre que, apesar das profundas diferenças na orientação política dos governos que implementaram o Trienal e o PAEG e também no desempenho destes planos, há autores que afirmam que, surpreendentemente, os dois planos eram muito parecidos. Lara Resende (1982) argumentou, por exemplo, que "o Paeg era um programa com diagnóstico e estratégia de combate à inflação bastante heterodoxos e, na realidade, muito semelhantes aos encontrados no Plano Trienal de Celso Furtado". (Lara Resende, 1982, p. 775) Cardoso (1970) foi ainda mais taxativo ao afirmar que os dois planos eram quase idênticos nas propostas. Segundo ele, "o Paeg enquanto plano em si não difere fundamentalmente do Plano Trienal". (Cardoso, 1970, p. 181) A diferença fundamental, no caso, estaria nas bases de poder dos governos Goulart e Castello Branco (idem).

Diante dessa discussão, o presente artigo tem por objetivo, justamente, comparar estes dois planos e avaliar o seu grau de similaridade. Ademais, pretende-se também analisar os fatores que explicam as enormes diferenças de desempenho obtidas pelo Trienal e pelo PAEG. Neste tocante, como ambos os planos eram compostos tanto por um programa de estabilização de curto prazo quanto por um conjunto de reformas estruturais voltadas para aumentar as taxas de crescimento no médio e longo prazos, é importante destacar que o artigo se concentrará apenas na análise dos programas de estabilização de curto prazo. Noutros termos, o objetivo é comparar as políticas de estabilização de curto prazo dos dois planos, avaliar a sua similaridade e discutir os porquês dos diferentes desempenhos.

A opção por restringir a análise às políticas de estabilização de curto prazo deve-se à importância destas políticas diante da conjuntura da época. Esta constatação está baseada no fato que, no contexto de inflação crescente e dificuldades nas contas externas em que o Trienal e o PAEG foram formulados, havia, em ambos os casos, um sentido de urgência no que tange à obtenção rápida de resultados favoráveis no combate a estes dois problemas. Desta forma, as políticas de esta- 
bilização consistiriam em uma primeira etapa dos planos, sendo que seu sucesso era condição quase que sine qua non para que as reformas pudessem ser implementadas com sucesso. Esta característica se fazia presente principalmente no caso do Plano Trienal, uma vez que foi colocado em prática em um contexto político muito conturbado, no qual o sucesso das medidas de estabilização era crucial para o presidente João Goulart obter legitimidade interna e externamente e, com isso, ter condições mínimas para colocar em prática sua agenda de reformas (Fonseca, 2004: p.609).

O artigo está dividido em três seções, além desta introdução e das conclusões. A primeira seção apresenta uma resenha das principais medidas de estabilização propostas pelo Plano Trienal, enquanto que a segunda seção é destinada ao PAEG. A terceira seção, por sua vez, consiste em uma análise comparativa das políticas de estabilização de curto prazo dos dois planos, na qual são apresentadas as semelhanças entre ambos e discutidas as razões que levaram os planos a resultados econômicos tão distintos.

\section{As Políticas de Estabilização de Curto Prazo do Plano Trienal}

O Plano Trienal foi elaborado em 1962, tendo como perspectiva estabelecer um conjunto de metas para a economia brasileira para o triênio 1963-65. A origem do plano está ligada ao plebiscito que, no início de 1963, definiria se o país retornaria ao presidencialismo ou continuaria no parlamentarismo, sistema implantando em 1961 como solução política para permitir a posse de João Goulart na presidência após a renúncia de Jânio Quadros. Neste contexto, o Trienal foi apresentado como o plano econômico que Goulart implementaria caso a opção pelo presidencialismo saísse vitoriosa (Furtado, 1997, p. 238).

O Plano Trienal (1962) ${ }^{1}$ procurou enfrentar os principais problemas que afetavam a economia brasileira no conturbado contexto da época. Neste contexto, apresentou, entre outras coisas, os seguintes objetivos: 1) taxas de crescimento da renda nacional da ordem de 7\%; 2) estratégia gradual de combate à inflação, de modo que a inflação

1 A síntese da versão original do plano foi publicada em 1962. Utiliza-se aqui a versão completa do plano que só foi publicada em 2011 pelo Centro Celso Furtado.

Est. Econ., São Paulo, vol. 43, n.1, p.139-166, jan.-mar. 2013 
de 1963 não excedesse a metade da taxa do ano anterior ${ }^{2}$ e que, em 1965, a taxa se aproximasse de 10\% ao ano; 3) salários reais crescendo a uma taxa idêntica à taxa de crescimento da produtividade da economia como um todo, bem como os ajustamentos em função do aumento do custo de vida; 4) refinanciamento da dívida externa, a qual - apesar de não ser particularmente grande - estava concentrada no curto e médio-prazos (Plano Trienal, 2011, p. 43).

No fundo, a principal ambição do plano era estabilizar a economia sem comprometer o crescimento econômico. No caso das medidas de estabilização de curto prazo, objeto principal do presente artigo, há alguns aspectos interessantes a destacar. O primeiro deles se refere às causas da inflação. Segundo a visão exposta no Plano Trienal, a inflação brasileira era causada pelos desequilíbrios da economia do país. Uma primeira fonte de inflação se devia aos desequilíbrios no setor público ocorridos em função do "rápido crescimento nos investimentos governamentais sem o apoio de um adequado esquema de financiamento" (Plano Trienal, 2011: 70). No caso, os déficits do Governo Federal levavam a um nível excessivo de emissão de papelmoeda, o que, por sua vez, pressionava os preços para cima (Plano Trienal, 2011, p. 46). Tratava-se, portanto, de um caso de inflação de demanda.

A outra fonte de desequilíbrios estava ligada à insuficiência crônica da capacidade de importar, a qual demandaria, por um lado, permanentes modificações na oferta interna e, por outro, desvalorizações cambiais. Essa fonte de inflação pode ser chamada de estrutural, uma vez que sua superação só poderia acontecer através do aprofundamento do processo de industrialização (Plano Trienal, 2011: p.67). Desta forma, como o objetivo deste artigo é estudar as políticas de estabilização de curto prazo, esta inflação estrutural não será objeto de análise, pois sua superação passava por reformas e mudanças estruturais que só poderiam ter efeitos no médio e longo prazos. ${ }^{3}$

A estratégia contida no Trienal para combate às pressões inflacionárias decorrentes da inflação de demanda estava baseada em medidas tradicionais de contenção de gastos e do crédito. O governo estimava que se o dispêndio potencial do Tesouro Nacional para o ano de 1963

2 Como a inflação em 1962 foi de 51,6\%, isto significava uma inflação em torno de $25 \%$.

3 Possivelmente, esta era a principal fonte de inflação para Celso Furtado, principal formulador do Plano Trienal. Segundo Bastos (2011), Furtado entendia que "a programação do desenvolvimento seria o único remédio estrutural contra a inflação” (Bastos, 2011: 444).

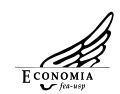


fosse efetivamente materializado, a pressão inflacionária se elevaria para $100 \%$, o que jogaria o país na hiperinflação. Neste sentido, o plano previa o corte de $1 / 3$ destes dispêndios, o que faria o déficit potencial de Cr\$ 774,9 bilhões cair para Cr\$ 300 bilhões $^{4}$ (Plano Trienal, 2011, p. 100).

No contexto desse esforço de redução dos desequilíbrios do setor público, cabe destacar que o plano previa um aumento de $40 \%$ para os salários do funcionalismo, o que, diante de uma inflação de 51,6\% em 1962, significava um reajuste que sequer repunha a inflação do ano anterior. Ademais, havia a proposta de reduzir progressivamente os subsídios ao consumo dados pelo governo, particularmente os subsídios ao trigo, combustíveis e lubrificantes derivados do petróleo. Segundo cálculos apresentados, o esforço de defesa destes preços teria representado uma perda de recursos financeiros superior a Cr $\$$ 60 bilhões em 1962 e que poderia chegar a valores muito superiores em 1963 (Plano Trienal, 2011, p. 101). A retirada desses incentivos provocaria fatalmente uma pressão inflacionária de curto-prazo, a chamada inflação corretiva. Todavia, a defesa desses preços também não estava colaborando no combate à inflação, pois "as emissões de papel-moeda efetuadas para atender ao pagamento dos subsídios tiveram certamente reflexo inflacionário maior do que o que se procurava evitar" (idem).

Apesar do peso atribuído ao ajuste do setor público, havia também medidas de ordem monetária e creditícia. Na verdade, havia um esquema de programação monetária, o qual estava associado justamente às metas fiscais estabelecidas. Neste contexto, a expansão prevista para os meios de pagamento em 1963 era da ordem de 34\%, pois esta expansão seria compatível com uma taxa de crescimento do PIB de 7\%, um aumento do nível geral de preços da ordem de $25 \%$ e a estabilização da relação dispêndio público sobre o PIB. Da mesma forma, estabeleceu-se que o crédito ao setor privado deveria crescer em montante correspondente à elevação do nível de preços mais o aumento do produto real, de modo que as políticas de redesconto e recolhimento compulsório da Sumoc e as carteiras do Banco do Brasil deveriam ser gerenciadas a partir destes tetos para a expansão (Plano Trienal, 2011, p. 47).

4 Segundo os cálculos realizados na programação financeira para 1963, "esse déficit é compatível com um nível de emissão de papel-moeda que permite reduzir a pressão inflacionária, de forma a que o incremento do nível de preços não supere a metade do observado no ano corrente" (Plano Trienal, 2011, p. 46). 
Todavia, há um outro elemento-chave em toda a formulação do plano: o papel da capacidade de importar como fator condicionante para a estratégia do Trienal de estabilizar a economia sem prescindir de taxas de crescimento econômico da ordem de 7\%. No caso, este fator tinha um peso muito grande, uma vez que a deterioração dos termos de troca e a concentração de compromissos financeiros a curto e médio prazos tinham reduzido de maneira significativa a capacidade de importar do país no início dos anos 1960. Neste contexto, o esforço de expandir a capacidade de importar passava por estímulos da atividade exportadora, o que, por sua vez, estaria ligado a uma política de realismo cambial (Plano Trienal, 2011: p. 111). ${ }^{5}$ Outro fator crucial associado à questão da capacidade de importar era o acesso ao financiamento externo. Como uma menor capacidade de importar pode reduzir as taxas de crescimento, a questão do financiamento externo passou a ser um fator chave no plano, uma vez que o financiamento externo pode, no curto prazo, expandir a capacidade de importar (Plano Trienal, 2011, p. 80; 107-111;133-135). As estatísticas e estimativas apresentadas no Trienal mostravam as dificuldades que o Brasil tinha no que tange às suas contas externas. Diante dos déficits em conta corrente e os pagamentos com amortizações de dívida, descontada a entrada de capitais, o país gerou - no biênio 1961-62 - um descoberto a ser refinanciado. Para que todos os compromissos destes dois anos fossem honrados sem que o país tivesse que apelar para novos empréstimos, teria sido necessário um nível de importações muito menor, o que, seguramente, teria afetado as taxas de crescimento do país. Para o período 1963-65, haveria pagamentos externos vultosos - sob a forma de amortizações e juros - e projeção de déficits em conta corrente e no balanço de pagamentos. ${ }^{6}$

Desta forma, diante desse contexto, os formuladores do Trienal eram taxativos: "torna-se claro que, simplesmente para manter o atual nível de importações, sem o que não será fácil defender a taxa de crescimento da economia, será necessário realizar um forte esforço de refinanciamento da dívida externa" (Plano Trienal, 2011, p. 8182). O refinanciamento da dívida era, portanto, aspecto fundamental do plano.

5 Ainda na parte da política cambial, o governo previa também a manutenção dos controles cambiais existentes e dos depósitos obrigatórios vinculados às vendas de cambiais e a possibilidade de ampliação da lista de produtos incluídos na categoria especial de importações (Plano Trienal, 2011: p.133).

6 Os dados apresentados no Trienal previam pagamentos ao exterior no triênio 1963-65 da ordem de US\$1,66 bilhões, e estimava déficits em transações correntes que, na soma do referido triênio, chegariam a US\$ 545 milhões (Plano Trienal, 2011, p. 81-82). 


\section{As Políticas de Estabilização de Curto Prazo do PAEG}

O golpe militar de abril de 1964 depôs João Goulart e instituiu - no dia 15 de abril - o marechal Humberto Castello Branco como presidente do país até 20 de janeiro de 1967. Diante da crise econômica que acometia o país, Castello Branco nomeou Octavio Gouveia de Bulhões e Roberto Campos para os cargos de ministro da Fazenda e do Planejamento, respectivamente. O Programa de Ação Econômica do Governo (PAEG) seria então lançado oficialmente em novembro de 1964, contendo as principais políticas e reformas pretendidas pela equipe econômica. ${ }^{7}$

O diagnóstico sobre as causas da inflação contido no PAEG apontava para três fatores: 1) os déficits públicos; 2) a expansão do crédito às empresas; 3) os aumentos salariais por cima dos ganhos de produtividade. Estes elementos provocariam a expansão dos meios de pagamento, causando, dessa forma, a propagação da inflação (PAEG, 1964, p. 28).

Os déficits públicos eram apontados como sendo capazes de, por si sós, causar uma elevação no nível geral de preços, tendo em vista o desequilíbrio que provocam entre a demanda e a oferta global. Assim, na visão exposta no plano, o saneamento do setor público seria condição indispensável - ainda que não suficiente - para o êxito do programa de estabilização (PAEG, 1964, p.29). Do ponto de vista da expansão do crédito para as empresas e dos aumentos salariais superiores aos aumentos de produtividade, não estaria claro até que ponto estes fatores seriam causas autônomas ou induzidas da inflação brasileira, porém afirmava-se, por outro lado, que "alguns indícios sugerem, todavia, que ultimamente a inflação brasileira estaria assumindo a tônica de inflação de custos". (PAEG, 1964, p.30) Neste contexto, pode-se argumentar que o plano identificava a existência de uma inflação de demanda - causada principalmente pelos déficits públicos - e de uma inflação de custos causada pelos aumentos salariais por cima da produtividade. Esta interpretação é corroborada por Roberto Campos, um dos principais formuladores do plano. Em seu livro de memórias, ao abordar o tema do diagnóstico do PAEG

7 No entanto, a verdade é que muitas medidas do PAEG já vinham sendo adotadas desde o primeiro semestre de 1964, ou seja, muito antes de o documento ser lançado. Neste sentido, houve a opção da equipe econômica de ir pondo em prática as políticas antes de divulgar um documento oficial que sistematizasse a estratégia a ser implementada. Por conseguinte, novembro de 1964 não é efetivamente o ponto de partida do PAEG. 
acerca das causas da inflação brasileira, Campos (1994) afirmou que "quanto às raízes do processo inflacionário, eu argüia que elas tinham variado no curso do tempo, mas ultimamente a responsabilidade primordial cabia aos déficits públicos e à contínua pressão salarial. Aqueles geravam inflação de procura e esta, inflação de custos". (Campos, 1994, p.576)

Apesar dos altos índices de inflação registrados no momento de sua implementação, o PAEG não recomendava, contudo, um tratamento de choque para resolver o problema. Segundo o documento oficial, o programa tinha a intenção de retomar o desenvolvimento, de modo que a política anti-inflacionária não poderia ameaçar a propensão a investir da economia e, tampouco, provocar a insolvência do setor empresarial (PAEG, 1964, p. 33). Uma estratégia radical de combate à inflação passaria pela eliminação quase total dos déficits públicos, de modo que seria necessário um corte substancial nos investimentos públicos, o que, necessariamente, teria efeitos sobre o crescimento econômico do país. Além disso, um tratamento de choque traria aumento do desemprego e demandaria o congelamento geral dos salários, o que seria socialmente indesejável. Por fim, o programa apontava a necessidade de uma inflação corretiva através da liberação de alguns preços da economia que estavam controlados, o que, na prática, condenaria uma estratégia de choque ao fracasso, uma vez que, logo de início, os preços subiriam em função da inflação corretiva (idem).

Diante desse contexto, o plano previa uma estratégia gradualista de combate à inflação, onde as metas sugeridas para os anos vindouros eram de 25\% em 1965 e 10\% em 1966. Para atingir este propósito, o plano estabelecia diretrizes para as políticas fiscal, monetária e creditícia, e também para a política salarial. Do ponto de vista das medidas na área fiscal, o governo previa redução dos gastos públicos e aumento de receitas. $\mathrm{Na}$ parte dos gastos, ficava estabelecido que a União deveria cortar despesas não prioritárias, corrigir os déficits de autarquias e de sociedades de economia mista. Quanto às receitas, estimavam-se aumentos em função da expectativa de recuperação nas taxas de crescimento econômico. No entanto, o ponto principal seria resultado da reforma tributária, que, entre outras coisas, estabelecia o aumento da base de incidência do imposto de renda e a ampliação dos impostos indiretos. Por fim, um elemento fundamental na esfera fiscal era o restabelecimento do mercado de títulos públi- 
cos a partir da introdução da correção monetária. Ao eliminar a lei da usura - que fixava um teto de $12 \%$ para a taxa de juros nominal - e lançar as Obrigações Reajustáveis do Tesouro Nacional (ORTNs), títulos cujo valor era defendido da desvalorização monetária causada pela inflação, o governo criaria novamente demanda para os títulos públicos, encontrando, por conseguinte, uma forma não inflacionária de financiar os seus déficits ${ }^{8}$ (PAEG, 196, p. 34; 53-55; 77-80).

Para o ano de 1964 que estava se encerrando, o governo previa um déficit de Cr\$ 1247 bilhões. Apesar do valor elevado, o documento salientava que em março de 1964, ainda no governo Goulart, a previsão do déficit do Tesouro era de $\mathrm{Cr} \$ 2001$ bilhões, de maneira que o novo governo teria o mérito de ter reduzido substancialmente o déficit potencial para o ano em questão. Quanto a 1965, a previsão era um déficit da ordem de Cr\$ 698 bilhões, o que, apesar de corresponder a um valor elevado, significava uma redução da razão déficit/PIB para 2,8\%, uma vez que em 1964 esta relação estava em $4 \%$. Concluiam os policy-makers do PAEG que esta redução sinalizava um menor impacto dos déficits governamentais sobre a inflação (PAEG, 1964, p. 53-56).

$\mathrm{Na}$ parte referente às políticas monetária e creditícia, o programa apontava duas diretrizes para evitar a expansão monetária excessiva: 1) redução dos déficits governamentais para evitar que as Autoridades Monetárias sejam passivamente obrigadas a emitir moeda; 2) controle do crédito ao setor privado (PAEG, 1964: 64). Neste tocante, cabe destacar uma dificuldade que surge em um contexto de inflação de custos: "deflagrada uma alta de custos de produção, ou as Autoridades Monetárias expandem seus empréstimos, ou condenam a economia a uma depressão, por falta de liquidez real". (PAEG, 1964, p. 63) Desta forma, havia a necessidade de controlar o crédito, sem, no entanto, provocar escassez de liquidez. Para tanto, definiu-se que os tetos globais de crédito às empresas deveriam ser reajustados proporcionalmente ao crescimento do Produto Nacional a preços correntes ou, alternativamente, ao crescimento do total dos meios de pagamento (PAEG, 1964, p. 34).

Quanto à política salarial implementada pelo PAEG, o objetivo principal era combater a inflação de custos provocada pelos aumentos

8 A introdução da correção monetária não se limitou, contudo, aos títulos públicos. Esta questão será tratada na próxima seção. 
salariais superiores aos aumentos de produtividade. ${ }^{9}$ Entendia-se que os reajustes salariais colocavam em movimento a chamada espiral inflacionária, de modo que era preciso "impedir que reajustamentos salariais desordenados realimentem irreversivelmente o processo inflacionário". (PAEG, 1964, p. 83) Nesse contexto, o princípio fundamental que deveria nortear a política salarial era que os salários reais só poderiam ser elevados pelo aumento da produtividade e aceleração do desenvolvimento, de modo que - no bojo do esforço de contenção do processo inflacionário - as medidas nesta área visavam eliminar a instabilidade dos salários reais sem, todavia, elevar a média dos mesmos (PAEG, 1964, p. 34).

Diante desta diretriz o governo estabeleceu que, durante a execução do plano anti-inflacionário, "os reajustamentos salariais sob controle do Governo Federal não sejam efetuados com espaçamento inferior a um ano, a partir da última revisão". (PAEG, 1964, p. 85) Adicionalmente, o governo criou uma regra salarial que tinha por finalidade eliminar o mecanismo de realimentação da inflação, sem, no entanto, provocar um arrocho excessivo como aquele que seria gerado por um congelamento geral de salários. Esta regra salarial estabeleceu que o salário reajustado deveria ser determinado de modo a igualar o salário real médio vigente nos últimos 24 meses, multiplicado por um coeficiente que traduzisse o aumento de produtividade do ano anterior, além de uma provisão para compensar o resíduo inflacionário esperado para o período em que vigorasse este salário reajustado (PAEG, 1964, p.85). Com isso, ao tentar reconstituir a média do salário dos últimos dois anos acrescida do aumento de produtividade e de uma parcela do resíduo inflacionário esperado, a regra salarial não repunha integralmente o poder aquisitivo do salário prevalecente logo após o último reajuste que este sofreu. Assim, ao não conceder aumentos salariais equivalentes à inflação registrada desde o último reajuste, a regra salarial quebrava a dinâmica da espiral inflacionária. ${ }^{10}$

\footnotetext{
9 A ideia de que a regra salarial do PAEG foi um mecanismo para combater a inflação de custos é apresentada, por exemplo, por Mário Henrique Simonsen, participante da equipe que formulou o PAEG. Segundo Simonsen (1974), "a fórmula da política salarial - uma das inovações mais originais do Programa do Governo Castelo Branco...foi aplicada com bastante rigor em 1965 e 1966, contendo francamente a inflação do lado dos custos". (Simonsen, 1974, p.83)

${ }^{10}$ Estas diretrizes da política salarial do PAEG foram oficializadas com a aprovação da Lei $\mathrm{n}^{\circ} 4725$ em julho de 1965. Todavia, mesmo antes disso, em fevereiro daquele ano, o aumento do salário mínimo já obedeceu os critérios da referida política salarial. Quanto ao funcionalismo público, a categoria não recebeu aumentos em 1965 e, em 1966, os aumentos seguiram as normas da Lei $n^{\circ}$ 4725 (Simonsen, 1970, p. 34).
} 
Por fim, há que se mencionar as medidas voltadas para enfrentar o problema das contas externas. A política cambial tinha como principal diretriz manter taxas de câmbio realísticas para estimular as exportações. O estímulo à exportação era considerado, por sinal, fator chave para o fortalecimento da capacidade de importar do país (PAEG, 1964: p.131-132). ${ }^{11}$

Outra fonte importante de preocupação dizia respeito à obtenção de fontes de financiamento externo. Neste quesito, o documento apontava que o principal problema não era o tamanho da dívida externa, mas sim o fato de $48 \%$ de seus encargos estarem concentrados nos anos de 1964 e 1965. Diante deste contexto, o documento enaltecia os esforços de renegociação da dívida externa que vinham sendo feitos desde o início do governo de Castello Branco no primeiro semestre de 1964, apontando para o sucesso das missões junto aos credores norte-americanos, europeus e aos japoneses. ${ }^{12}$

\subsection{Trienal versus PAEG: Análise Comparativa}

A apresentação das principais propostas de estabilização de curto prazo do Trienal e do PAEG já fornece um panorama inicial acerca das semelhanças e diferenças entre ambos. No entanto, a análise da questão se torna mais simples a partir de um quadro-resumo (Tabela 1) que sintetize as principais características dos dois planos.

11 Outro aspecto considerado prioritário no que tange à política cambial era a unificação das diferentes taxas cambiais em um mercado unificado, livre e flexível como a prioridade principal para esta política. O plano previa ainda medidas de liberalização, como a eliminação de taxas preferenciais (exceto para o café) e também dos depósitos compulsórios (PAEG, 1964, p. 48).

12 No que concerne às relações com investidores estrangeiros, o PAEG apontava também para os benefícios do capital estrangeiro no esforço de desenvolvimento de países atrasados, uma vez que, além de aumentar a capacidade de importar do país, este também teria efeitos na produtividade da economia a partir de transferências de tecnologia. Desta forma, o programa propunha uma nova Lei de Remessa de Lucros que retirasse controles sobre o movimento de capital estrangeiro e facilitasse a atração destes capitais (PAEG, 1964, p. 134-144). 
Tabela 1 - Políticas de estabilização de curto prazo: Trienal $v s$ PAEG

\begin{tabular}{lll}
\hline & \multicolumn{1}{c}{ Trienal } & \multicolumn{1}{c}{ PAEG } \\
\hline Diagnóstico da inflação & $\begin{array}{l}\text { Inflação de demanda causada por déficits } \\
\text { públicos/ Inflação estrutural }\end{array}$ & $\begin{array}{l}\text { Inflação de demanda causada por déficits } \\
\text { públicos/ Inflação de custos causada por } \\
\text { aumentos salariais }\end{array}$ \\
\hline Estratégia de combate & Gradualista & Gradualista \\
\hline Inflação corretiva & Sim & Sim \\
\hline Política Fiscal & Contenção dos gastos públicos & $\begin{array}{l}\text { Contenção dos gastos públicos/ Introdução } \\
\text { da correção monetária }\end{array}$ \\
\hline Política Monetária & $\begin{array}{l}\text { Controle sobre a expansão monetária e } \\
\text { do crédito }\end{array}$ & $\begin{array}{l}\text { Controle sobre a expansão monetária } \\
\text { e do crédito/ Introdução da correção } \\
\text { monetáriaetária }\end{array}$ \\
\hline Política Cambial & Realismo cambial & Realismo cambial \\
\hline Política Salarial & Os salários devem crescer juntamente com \\
a produtividade/ Nenhuma regra salarial & Estabelecimento de uma regra salarial \\
\hline
\end{tabular}

Fonte: Elaboração própria.

A partir do quadro, é possível perceber semelhanças importantes entre o Plano Trienal e o PAEG. Ambos os planos apontaram para a necessidade de uma inflação corretiva prévia ao esforço de estabilização. Em função desta inflação corretiva e dos altos custos sobre as taxas de crescimento e desemprego, a opção de um tratamento de choque contra a inflação foi descartado nos dois casos. Assim, os dois planos basearam-se em uma estratégia gradualista de estabilização, onde, por sinal, a expectativa em ambos os planos era que a taxa de inflação convergisse para $10 \%$ no último ano de vigência do plano. Nota-se, ademais, que as políticas fiscal e monetária/creditícia seguiam a mesma orientação (contracionista) no Trienal e no PAEG. Por fim, há, nos dois casos, a opção por uma política de realismo cambial.

Contudo, é possível também perceber diferenças entre os dois planos a partir do quadro-resumo. A primeira delas está associada à introdução da correção monetária por parte do PAEG, elemento que não estava presente no caso do Plano Trienal. A correção monetária tinha por finalidade atenuar os efeitos distorcivos típicos dos processos inflacionários, o que, nas palavras de Simonsen (1970), permitiria uma convivência pacífica com a inflação ${ }^{13}$ (Simonsen, 1970, 184;

13 O documento do PAEG listou nove distorções econômicas e sociais causadas pela inflação, como, por exemplo: a desorganização do mercado de crédito, distorção dos coeficientes de rentabilidade, distorção do mercado cambial, desestímulo aos investimentos sociais, impossibilidade de previsão financeira e prêmio à especulação (PAEG, 1964, p.30-32). 
191). Como um plano gradualista de combate à inflação prevê um processo de estabilização mais lento do que o prevalecente em um tratamento de choque, a introdução de um mecanismo que atenuasse os efeitos deletérios da inflação no curto prazo facilitaria a aceitação do plano por parte do público e criaria maiores chances de sucesso para o duplo objetivo de estabilizar gradualmente e, ao mesmo tempo, retomar o crescimento econômico (Hermann, 2005, p.73).

Neste contexto, o governo Castello Branco introduziu, a partir de 1964, uma série de leis criando a correção monetária para, entre outras coisas, os débitos fiscais em atraso, os empréstimos concedidos pelo sistema financeiro, os aluguéis e a tarifação dos serviços de utilidade pública. No caso, merece destaque a introdução das ORTNs, títulos da dívida pública com correção monetária, que revigoraram a procura por estes títulos, reduzindo a necessidade de financiar o déficit público através de emissão monetária ${ }^{14}$ (Simonsen, 1970, p.184-191). Desta forma, conforme sugerido no quadro-resumo, a introdução da correção monetária afetou, no caso do PAEG, tanto a gestão da política fiscal quanto da política monetária.

O segundo ponto de diferença entre o Trienal e o PAEG está relacionado com as causas da inflação identificadas em cada um dos planos. Este ponto de distinção é bastante importante, pois resultará em diferenças nas políticas de estabilização recomendadas. Os planos concordavam quanto à existência de uma inflação de demanda, o que justificava as propostas semelhantes nas áreas fiscal e monetária.

No entanto, reconheciam também outras fontes de inflação: o Trienal identificou uma inflação estrutural e o PAEG apontou para a existência de inflação de custos via salários. Por demandar ajustamentos de médio e longo prazos, a inflação estrutural não foi abordada neste artigo. ${ }^{15} \mathrm{~A}$ inflação de custos, por sua vez, permite ajustamentos de curto prazo. Neste contexto, o reconhecimento por parte do PAEG de uma inflação de custos via pressão salarial gerará a principal diferença de política econômica entre os dois planos: a regra salarial do PAEG (Lara Resende, 1982: p.776).

14 De fato, em 1965, 55\% do déficit público foi financiado via títulos da dívida pública e, em 1966, este valor se elevou para 86\% (Hermann, 2005, p. 82 apud Simonsen, 1970, p.34-37).

15 Todavia, o reconhecimento por parte do Trienal que parte da inflação era de caráter estrutural tinha consequências em termos de política econômica. No caso, se a inflação era em parte estrutural, a resolução completa do processo inflacionário só seria possível com reformas estruturais (Fonseca, 2004, p.609). 
A identificação desta diferença-chave leva a uma questão relevante: seria a política salarial do PAEG razão suficiente para explicar as diferenças de desempenho entre os planos? A resposta a esta pergunta está no contexto político interno e, além disso, nas relações internacionais, com destaque aqui para o tratamento diferenciado dado pelos norte-americanos ao governo Castello Branco em detrimento do governo de João Goulart. Estes dois aspectos merecem uma discussão pormenorizada.

No que tange ao contexto político, o primeiro elemento a destacar remete às especificidades do governo de João Goulart. O passado de Goulart vinculado aos trabalhadores e a Getúlio Vargas encorajava os sindicatos e movimentos sociais em suas reivindicações.

De fato, a ascensão ao poder de um político simpático às causas destes grupos criava neles a confiança de que este seria um governo atento aos seus anseios e à agenda de reformas por eles demandada. Mais do que isso, o governo Goulart sinalizava a oportunidade de obter ganhos salariais reais, pois - conforme mostrou Colistete (2007) - os salários reais cresceram menos do que a produtividade do trabalho na indústria manufatureira na maior parte do período entre 1954 e 1962, o que significou perda de participação dos trabalhadores no produto industrial no período em questão (Colistete, 2007: p.116).

Todavia, o passado de Goulart causava grandes preocupações nos setores mais conservadores, os quais não toleravam reformas progressistas e políticas lenientes com os sindicatos. Diante de uma propensão ao golpismo por parte dos conservadores - o qual já vinha desde os anos 1950 - e, ademais, de um contexto internacional de Guerra Fria intensificado nas Américas pela Revolução Cubana de 1959, esta polarização criava para o governo Goulart um cenário político de grande instabilidade. Este cenário era ainda mais problemático se levarmos em conta que o contexto econômico também era desfavorável em função das taxas de inflação em alta e das taxas de crescimento em baixa.

A partir desta conjuntura complexa, Goulart procurou, inicialmente, contemporizar. Contudo, esta tentativa de conciliar os interesses conflitantes que havia no cenário político da época acabou não dando certo. As concessões feitas aos diferentes grupos nunca lhes pareciam suficientes: todos os grupos queriam uma tomada de posição mais 
contundente do presidente na direção por eles almejada, de modo que as conspirações se multiplicavam por todos os $\operatorname{lados}^{16}$ (Moniz Bandeira, 2010, p.205-206; Melo et al., 2008, p.95-96).

A impossibilidade de conciliar as demandas dos diferentes grupos ficou clara no contexto das políticas de estabilização. No começo de 1963, o governo estava efetivamente comprometido com as políticas de combate à inflação programadas pelo Plano Trienal. Neste contexto, foram tomadas as medidas de inflação corretiva, como a suspensão dos subsídios ao consumo, a correção das tarifas de transporte urbano, o reajuste do salário mínimo e, em abril, a desvalorização da taxa de câmbio. No primeiro trimestre de 1963, a política fiscal foi restritiva, tendo havido ainda uma forte redução da liquidez real da economia (Lara Resende, 1982, p.763-765). Além disso, do ponto de vista da política salarial, o aumento sugerido para o funcionalismo foi de $40 \%$, valor que não repunha integralmente a inflação passada e era também inferior aos reajustes que vinham sendo realizados no setor privado (Macedo, 1970, p. 61-62).

Todavia, nos três primeiros meses de 1963, a inflação chegou a 16\%, ou seja, mais da metade da inflação planejada para todo o ano. A razão para tal avanço dos preços foi justamente a política de inflação corretiva que, entre outras coisas, provocou um aumento de $100 \%$ no preço do trigo e de $70 \%$ no preço doméstico do petróleo, bem como a elevação de 56,25\% no salário mínimo (Lara Resende, 1982, P.763; Macedo, 1970, P. 62; Melo et al., 2008, p. 95).

Neste contexto de inflação em alta, os sindicatos reclamaram por aumentos salariais maiores. O governo até tentou resistir, mas o Congresso aprovou em maio um aumento de $70 \%$ para o funcionalismo (contra os $40 \%$ previstos), o qual acabou sendo acatado pelo governo federal. Com isso, "o choque de custos foi repassado aos preços e teve como reação, um choque nos salários nominais, rea-

\footnotetext{
${ }^{16}$ Neste contexto, segundo Skidmore (1992), os extremistas ganhavam espaço no espectro político brasileiro. De um lado, havia os antigetulistas tradicionais que incluíam lideranças dentro das Forças Armadas - como os ex-ministros Denys e Heck - e segmentos do empresariado, como Júlio de Mesquita Filho, proprietário do jornal O Estado de São Paulo. Do outro lado, havia a chamada esquerda radical, a qual era encabeçada por instituições sindicais e movimentos sociais, como o Comando Geral dos Trabalhadores (CGT) e as Ligas Camponesas, e tinha como estratégia aproveitar-se de crises políticas "a fim de provocar uma abrupta transferência de poder". Neste grupo, Leonel Brizola era o líder político mais importante (Skidmore, 1992, p.273-276).
} 
limentando a chamada espiral inflacionária ${ }^{17 "}$ (Melo et al., 2008: 102). Por sua vez, a pressão de custos provocou a queda da liquidez do setor privado que também passou a pressionar pela expansão monetária (Macedo, 1970, p. 64).

O resultado desta combinação de fatores foi que, apesar do esforço do governo na adoção de políticas monetária e fiscal restritivas, a inflação não foi controlada. Diante da perda de controle sobre a inflação e das dificuldades externas, o ministro da Fazenda, San Tiago Dantas, renunciou ao posto em junho. ${ }^{18} \mathrm{Com}$ isso, diante do fracasso no atingimento dos objetivos no primeiro semestre e da saída de San Tiago Dantas, é possível dizer que, no meio do ano de 1963 o Trienal já tinha sido abandonado. ${ }^{19}$

O fracasso do Trienal não significou, todavia, uma renúncia imediata em relação ao intento de estabilizar os preços. Como sucessor de San Thiago Dantas, Goulart indicou Carvalho Pinto, político paulista simpático às políticas de estabilização ortodoxas. Apenas quando Carvalho Pinto deixou o governo, no final de 1963, é que Goulart explicitamente optou pela heterodoxia. Neste momento, ele indicou para a pasta da Fazenda Ney Galvão, um político gaúcho de pouca expressão nacional. Esta escolha sinalizou o desejo de Goulart de controlar mais de perto os rumos da política econômica (Fonseca, 2004, p. 616).

De fato, após o fracasso do Trienal, Goulart foi aos poucos desistindo de sua tentativa de ganhar a adesão dos segmentos conservadores, aproximando-se, com isso, dos grupos que constituíam a sua base política original. Como colocou Fonseca (2004), "Goulart parecia cansado das tentativas infrutíferas de buscar aceitação e credibilidade por meio de medidas restritivas, demoradas para surtir efeitos positivos, mas rápidas para afastá-lo de sua base política”. (Fonseca, 2004, p. 617) Esta opção acirrou os ânimos e inflamou os setores

${ }^{17}$ Conforme observou Sola (1998), "os reajustes para o servidores federais estabeleciam os parâmetros para os estatais e os municipais". (Sola, 1998, p.353) Desta forma, os aumentos para o funcionalismo tinham um importante papel de sinalização.

18 Para Sola (1998), foi no segundo trimestre de 1963 que o governo Goulart começou a perder o controle sobre a situação política e econômica do país. Esta perda de controle deveu-se a dois motivos: 1) a alta inflação registrada no primeiro trimestre; 2) o fracasso das negociações em Washington (Sola, 1998, p.366). As dificuldades no front externo serão abordadas mais adiante.

${ }^{19}$ Entre outras coisas, o orçamento de 1964 enviado ao Congresso ignorava as metas previstas pelo plano (Fonseca, 2004, p. 614). 
golpistas, fazendo com que a fase final do governo Goulart fosse marcada por uma crescente radicalização Neste contexto, os setores que tinham pretensões golpistas ganham a adesão de conservadores moderados e, igualmente, do governo norte-americano que já vinha acompanhando com receio o desenrolar dos acontecimentos no Brasil. O desfecho deste processo foi o golpe militar deflagrado em abril de $1964 .^{20}$

A gestão da política econômica por parte do governo Castello Branco enfrentou um clima muito menos turbulento, uma vez que as limitações políticas que João Goulart sofria não estavam presentes no caso dos militares. Primeiramente, o fato de o país estar em uma ditadura em 1964 dava aos governantes uma capacidade de ação muito maior, posto que segmentos descontentes não teriam a liberdade de expressar a sua insatisfação como ocorre em sociedades democráticas. Em segundo lugar, diferentemente do que ocorrera com Goulart, o governo Castello Branco não tinha nenhuma vinculação com os sindicatos e, portanto, não possuía qualquer receio em adotar uma política de arrocho salarial. ${ }^{21}$ Falando sobre este conturbado período de meados da década de 1960, Moniz Bandeira afirmou que "a crise econômica atingira um ponto que impunha uma definição de classe... a questão consistia em saber de que lado se cortaria a carne". (Moniz Bandeira, 2010, p. 212) Neste contexto de polarização, os vitoriosos no golpe de 1964 tinham muita clareza acerca do lado em que estavam e quais eram as suas bases de legitimação.

Com isso, a dupla Campos-Bulhões acrescentou às políticas de estabilização do PAEG um elemento que não estava presente no Trienal: a compressão dos salários através da lei salarial. A inclusão deste item acabou tendo um papel crucial nos diferentes resultados alcançados pelos dois planos (Lara Resende, 1982, p.776). Se no caso do Trienal o choque de custos via inflação corretiva provocou uma espiral inflacionária, a regra salarial do PAEG, ao impedir o repasse integral da inflação para os salários nominais, quebrou a dinâmica da espiral inflacionária. Em outras palavras, conforme sugere Lara Resende (1982), o governo militar resolveu o impasse distributivo através da compressão salarial (Lara Resende,

20 Para detalhes, ver Skidmore (1992) e Fonseca (2004).

${ }^{21}$ Como sugerem Melo et al. (2008), "o compromisso assumido com a classe trabalhadora de melhorar suas condições de vida impedia uma política de arrocho salarial, como a praticada posteriormente pelos governos militares como forma de combate à inflação". (Melo et al. 2008, p. 104). 
1982, p. 802; Melo et al., 2008, p.102-103). Um exemplo desta redução salarial pode ser vista no Gráfico 1 , o qual apresenta a evolução do salário mínimo real na cidade do Rio de Janeiro. ${ }^{22}$

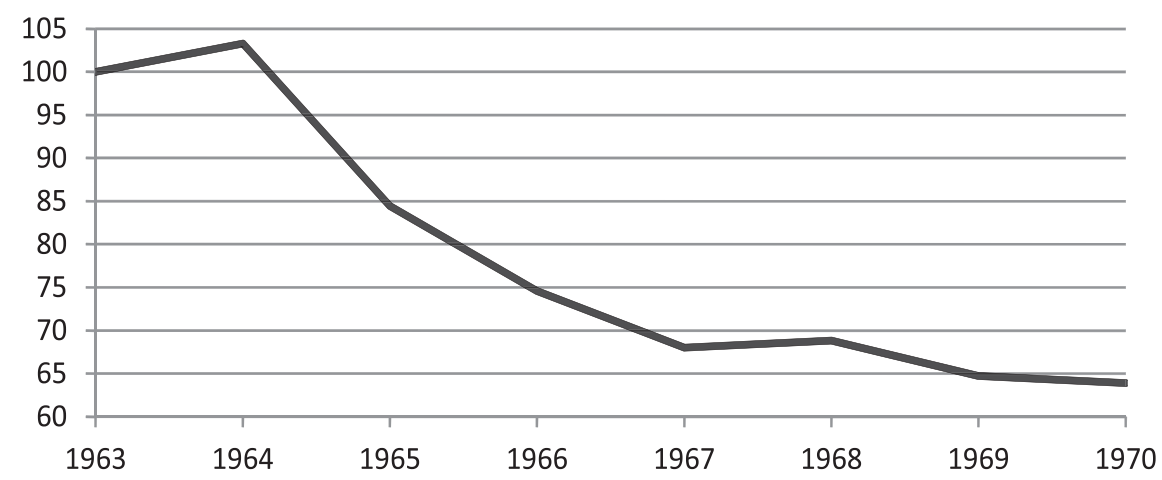

Gráfico 1 - Índice de salário mínimo real na cidade do Rio de Janeiro no mês de reajuste $(1963=100)$ (deflator: índice de custo de vida - RJ)

Fonte: Elaboração própria baseada em Lara Resende (1982) apud Fundação IBGE.

O impacto da inflação corretiva como detonador do processo de espiral inflacionária em 1963 e a impossibilidade política de o governo Goulart apelar para o arrocho salarial levam, naturalmente, ao questionamento se não teria sido melhor para Goulart não ter adotado estas medidas de inflação corretiva no início de seu governo. Malan (1984) mostrou, por exemplo, que, no começo dos anos 1960, desvalorizações cambiais não eram muito promissoras no que concerne ao seu objetivo de elevar a receita total em dólares das exportações brasileiras (Malan, 1984, p. 100). Além disso, a adoção de medidas de desvalorização cambial e realismo tarifário em uma economia com grande conflito distributivo e em um contexto de inflação alta era, no mínimo, uma temeridade (Melo et al., 2008, p.102).

O problema era que a adoção de medidas como o realismo cambial fazia parte do pacote de ajustes tradicionalmente recomendado pelo Fundo Monetário Internacional e, como o governo brasileiro, necessitava negociar com a instituição, era importante incluir medidas desta

\footnotetext{
22 O mês de reajuste não foi o mesmo em todos os anos. Em 1963, o reajuste ocorreu em janeiro, em 1964 o mês de reajuste foi fevereiro, entre 1965 e 1968 março e, no biênio 1969-70, o mês de reajuste foi maio.
} 
natureza $^{23}$ (Skidmore, 1992, p. 292). Desta maneira, se o governo Goulart não podia, por exemplo, conter salários devido a compromissos sociais e questões políticas, também era complicado renunciar às medidas de inflação corretiva. ${ }^{24}$ Assim, no esforço de compatibilizar interesses divergentes, o Plano Trienal acabou incorporando uma combinação inconsistente de medidas de inflação corretiva com a ausência de medidas de contenção da espiral inflacionária, o que inviabilizava qualquer chance de sucesso das medidas de estabilização ${ }^{25}$ (Melo et al., 2008, p.102).

Neste tocante, para finalizar a discussão sobre as políticas de estabilização, há que se fazer alguns comentários acerca do papel das políticas de contenção de demanda no desempenho dos dois planos. No caso, há pelo menos duas razões para ter cautela no que concerne à importância destas políticas como fator explicativo do melhor desempenho do PAEG no combate à inflação. Em primeiro lugar, cabe destacar o próprio comportamento das políticas macroeconômicas do PAEG. Pelo lado fiscal, houve, de fato, uma queda expressiva do déficit do governo de 4,2\% em 1963 para 1,1\% em 1966, mas o ajuste se deu muito mais por aumentos de receita do que por esforços de corte de gastos (Simonsen, 1974: p. 83; Lara Resende, 1990: 218). O comportamento das políticas monetária e creditícia, por sua vez, oscilou ao longo do tempo, o que impossibilita dizer que tiveram um comportamento contracionista durante todo o período 196466. Em segundo lugar, é difícil crer que havia pressões de demanda relevantes quando do início do PAEG. ${ }^{26}$ A economia brasileira ficou estagnada em 1963 e, como houve vultosos investimentos durante o Plano de Metas, é de se imaginar que a capacidade ociosa estivesse

${ }^{23}$ Em seu livro de memórias, Celso Furtado afirma que, ao elaborar o Plano Trienal, ele "tivera o cuidado de incluir um conjunto de providências estabilizadoras que estavam longe de ferir a sensibilidade ortodoxa dos técnicos do FMI" (Furtado, 1997, p.251).

${ }^{24}$ Neste tocante, é importante destacar que não se pretende aqui argumentar que para controlar a inflação bastava arrochar os salários e que, desta forma, o que teria faltado ao Trienal foi apenas firmeza no controle salarial. O controle dos aumentos salariais é apenas uma forma de políticas de rendas e, por seu caráter regressivo, é, inclusive, socialmente indesejável. O problema em 1963 era que "dada a exacerbação das demandas sociais e com os conflitos de interesse daí resultantes era praticamente impossível implementar políticas de rendas capazes de coordenar o sistema de formação de preços público e privado" (Melo et al., 2008: 102).

25 Segundo Sola (1998), os técnicos que formularam o Trienal subestimaram os efeitos das políticas de estabilização. Para ela, os técnicos "excluíram de seu horizonte a hipótese de uma espiral preços-salários, muito provável diante da liberalização progressiva do câmbio, dos ajustamentos nas tarifas públicas em particular, da eliminação dos subsídios ao trigo e ao petróleo", de modo que "tudo indica ter predominado um cálculo político bem preciso fundado em uma análise demasiado otimista da relação de forças existente”. (Sola, 1998, p.275)

${ }^{26}$ Devo este ponto a Carlos Pinkusfeld Bastos. 
elevada no início de 1964. Ademais, os índices de liquidez real também registraram contração no primeiro trimestre de 1964. Assim, conforme sugeriu Lara Resende (1990), é razoável supor que políticas de contenção de demanda não fossem recomendáveis para aquele contexto (Lara Resende, 1990: 225-230).

Contudo, além da sua incapacidade de equacionar o problema da inflação no contexto de conflito distributivo, o Plano Trienal sucumbiu também a outro problema: o estrangulamento externo. No caso, conforme visto anteriormente, a situação das contas externas brasileiras em fins de 1962 e início de 1963 era extremamente problemática e, como os próprios formuladores do Plano Trienal reconheciam, a retomada do crescimento econômico passava necessariamente pela obtenção de novos empréstimos e reescalonamento das dívidas antigas com os credores.

Segundo as contas apresentadas no plano, a estimativa era que, para manter a capacidade de importar do país, seria necessário US $\$ 1,5$ bilhão no triênio 1963-65. Sem estes recursos, havia duas saídas apenas para tentar minimizar os problemas nas contas externas: 1) desvalorizar a taxa de câmbio, o que impactaria na inflação; 2) contrair a economia, de modo a reduzir a absorção doméstica e, com isso, gerar saldos comerciais. Assim, na ausência de ajuda externa, qualquer um dos caminhos escolhidos implicaria o abandono do intento de promover a estabilidade de preços sem renunciar ao crescimento econômico.

Diante deste quadro adverso, o ministro da Fazenda San Tiago Dantas viajou em março de 1963 aos Estados Unidos para negociar uma nova ajuda externa e para reescalonar com os credores internacionais a dívida do país. Em particular, a missão brasileira pretendia alcançar três objetivos: "liberação de US\$ 153 milhões do Eximbank e da Aid; novos empréstimos montando a US\$150 milhões do Eximbank, US\$ 200 milhões da Aid e US\$ 140 milhões da PL 480 (trigo) e reescalonamento dos pagamentos vincendos em 1963/64" (Sochaczewski, 1993, p. 218).

O problema é que os norte-americanos não estavam dispostos a dar a ajuda que o Brasil solicitava e necessitava. Desde o final de 1962, o governo dos Estados Unidos procurou deixar claro para a administração Goulart que a ajuda financeira estaria condicionada ao 
cumprimento de uma série de requisitos por parte dos brasileiros. ${ }^{27}$ A primeira destas condições era a adoção de um plano de estabilização que tinha por fim garantir aos credores públicos e privados norte-americanos que os compromissos financeiros do Brasil seriam honrados. Neste contexto, recomendava-se também que o governo brasileiro reatasse as relações com o FMI. Um segundo ponto seria o afastamento do Brasil da chamada politica externa independente e a adoção de uma política externa mais alinhada com os Estados Unidos. ${ }^{28}$ Outro ponto relevante dizia respeito à encampação de empresas norte-americanas, em particular a encampação no Brasil da American \& Foreign Power (AMFORP) e de uma subsidiária da International Telephone \& Telegraph Company (ITT) que fora desapropriada por Leonel Brizola no seu período como governador do Rio Grande do Sul. No caso, os norte-americanos exigiam que os brasileiros comprassem as empresas e pagassem o preço justo por elas. ${ }^{29}$ Por fim, o ponto possivelmente mais importante era de ordem política: Goulart deveria afastar de seu governo figuras supostamente comunistas ou antiamericanas e, adicionalmente, deveria combater a presença destes elementos na atividade sindical (Loureiro, 2011: p.3-9; Sola, 1998: p.372-375).

Conforme mostra Loureiro (2011), o governo Goulart procurou, inicialmente, atender as demandas do governo americano. $\mathrm{O}$ plano de estabilização (Plano Trienal) foi implementado de início com rigor, o que gerou elogios da parte de membros do governo Kennedy. Ademais, as relações com o FMI foram reatadas e uma visita de técnicos do Fundo foi marcada. Quanto à encampação das empresas americanas, em janeiro de 1963 o governo brasileiro acertou com a ITT uma compensação financeira pela expropriação da subsidiária da empresa no Rio Grande do Sul. O único ponto em que Goulart não cedeu foi na exoneração de membros do governo, supostamente comunistas, pois o governo temia os efeitos políticos que as exonerações pudessem provocar. Ainda assim, o governo criou a União Sindical dos Trabalhadores (UST), uma nova central sindical que

${ }^{27}$ A discussão sobre as negociações entre Brasil e Estados Unidos durante o primeiro semestre de 1963 está, fundamentalmente, baseada em Loureiro (2011).

${ }^{28} \mathrm{O}$ Brasil não vinha se alinhando com os Estados Unidos na proporção em que Washington gostaria, como, por exemplo, na reunião de Punta del Este quando o país se absteve na votação que expulsou Cuba da Organização dos Estados Americanos (OEA).

29 Segundo Ribeiro (2006), John Kennedy estava sob pressão em função do lobby da ITT para pressionar os brasileiros (Ribeiro, 2006, p. 177-179). Ademais, vigorava naquele momento a emenda Hickenlooper, que vetava a concessão de ajuda a países que expropriassem companhias americanas (Ribeiro, 2006, p. 176-177). 
tinha por finalidade reduzir o poder dos comunistas nos movimentos organizados de trabalhadores (Loureiro, 2011: p. 10-13; 20).

Todavia, apesar de todos os esforços do governo Goulart para atender as demandas feitas por Washington, a ajuda oferecida pelos norte-americanos à missão de San Tiago Dantas foi decepcionante. O governo Kennedy alegou que o déficit da balança de pagamentos norte-americana inviabilizava uma ajuda no montante pleiteado pelos brasileiros, mas aparentemente as questões políticas foram a razão principal: os norte-americanos insistiam no problema de uma suposta infiltração comunista no governo brasileiro. No fundo, os norte-americanos quiseram manter Goulart sob pressão para que ele cumprisse toda a agenda de demandas de Washington, o que mostra a total falta de sensibilidade em relação ao contexto político brasileiro, bem como pouco reconhecimento aos esforços que já vinham sendo feitos (Loureiro, 2011: p. 15-16; 26). Assim, as condições estabelecidas no acordo final firmado entre Brasil e Estados Unidos (acordo Dantas-Bell) estabeleceram que o Brasil obteria recursos da ordem de US\$ 398,5 milhões, mas apenas US\$ 84 milhões seriam liberados de imediato (Fonseca, 2004, p.612). Ademais, a liberação dos recursos ficaria condicionada ao cumprimento das medidas de estabilização do Trienal e ao pagamento de indenização no caso AMFORP. Este resultado final do acordo dava algum fôlego, mas não resolvia o estrangulamento externo brasileiro: "Dantas pretendia desembarcar no Rio de Janeiro possuindo recursos suficientes para bancar cambialmente o Plano Trienal até 1965 e agora ele não tinha compromisso definitivo nem mesmo para fazer face ao ano que corria". ${ }^{30}$ (Ribeiro, 2006, p. 200).

Ao mesmo tempo, o resultado obtido e a necessidade de retomar o processo de compra das empresas americanas poderiam inflamar o já turbulento contexto político interno. Em suas memórias, Roberto Campos (1994) relata que advertiu os americanos que - do ponto de vista do clima político prevalecente no Brasil à época - as únicas formas de San Tiago Dantas sair fortalecido da missão brasileira a Washington seriam as posições extremas. Noutras palavras, a solução passava ou por uma ruptura de negociações que canalizaria o apoio dos segmentos nacionalistas ou uma grande vitória externa que demonstrasse claramente o apoio internacional (Campos, 1994, p. 514).

\footnotetext{
${ }^{30}$ Uma nova oportunidade foi desperdiçada quando da visita do FMI, já que com o stand-by o governo brasileiro ganharia fôlego. Todavia, os técnicos do FMI não deram o aval ao plano gradualista (Loureiro, 2011: p.16).
} 
Todavia, o acordo Dantas-Bell era justamente um caso intermediário e, como tal, poderia ter efeitos políticos desastrosos.

As repercussões do acordo Dantas-Bell comprovaram os temores de Campos: a recepção foi péssima nos círculos da esquerda brasileira ${ }^{31}$ e, entre outras coisas, gerou uma acalorada discussão sobre o preço que se deveria pagar pela AMFORP. O resultado desta contenda foi a interrupção das negociações e o estabelecimento de uma comissão para avaliar o real valor da empresa. No bojo deste processo, o ministro San Tiago Dantas, que já vinha desgastado pelos resultados do Plano Trienal, ficou ainda mais enfraquecido e veio a sair do governo em junho daquele ano.

Com a saída de San Tiago Dantas, os norte-americanos perderam de vez a confiança no governo brasileiro, de modo que os créditos negociados por Dantas que dependiam da continuidade do plano de estabilização ficaram congelados e as perspectivas de obtenção de nova ajuda externa se tornaram quase nulas (Moniz Bandeira, 2010: p.224-229). Na ausência de recursos externos, as opções eram desvalorizar a taxa de câmbio ou contrair a economia em função da menor capacidade de importar. Diante do quadro inflacionário já deteriorado, não era possível recorrer a novas desvalorizações cambiais. ${ }^{32}$

Com isso, o crescimento quase zero registrado em 1963 ajudou a melhorar o saldo em transações correntes, o qual registrou um déficit inferior ao dos dois anos anteriores. Ainda assim, o balanço de pagamentos do país fechou com déficit em 1963, o qual foi financiado através da perda de reservas em ouro e da contratação de empréstimos - em termos desfavoráveis - com bancos privados (Malan, 1984, p. 104).

Quando o novo governo assumiu em 1964, a situação das contas externas era, portanto, tão ou mais dramática do que no ano anterior. No entanto, os norte-americanos eram simpáticos ao regime militar que ascendeu ao poder após o golpe militar de abril. Ribeiro (2006) relata com detalhes a boa vontade do governo dos Estados Unidos

${ }^{31}$ Brizola chegou a classificá-lo como crime de lesa-pátria (Moniz Bandeira, 2010, p. 219).

${ }^{32}$ A última desvalorização oficial do cruzeiro ocorrera em abril de 1963. Como ao longo do ano a taxa de câmbio real permaneceu valorizada em função da alta inflação doméstica, o governo tentou, em novembro daquele ano, compensar as perdas dos exportadores através da Instrução 258 da SUMOC, a qual introduziu um sistema de bonificação aos exportadores (Fonseca, 2004, p. 617). 
com o governo incumbente e a expressiva ajuda fornecida ao Brasil para impedir que o novo regime sucumbisse economicamente.

De imediato, os brasileiros receberam um empréstimo de US $\$ 50$ milhões de dólares, o qual, contudo, estava condicionado à resolução do caso AMFORP. No ano de 1964, credores privados americanos prorrogaram dívidas brasileiras da ordem de US\$ 56 milhões ${ }^{33}$ (Ribeiro, 2006, p. 297-302). Ao longo dos anos de 1964 e 1965, houve um grande esforço da Usaid de mobilizar recursos e ajuda para viabilizar um bom desempenho da economia brasileira.

Em 1965, a ajuda externa ao Brasil somou US\$ 650 milhões, o que equivalia a 3\% do PIB brasileiro do ano anterior. Deste montante, 250 milhões vieram da Usaid e do Eximbank, 100 milhões foram concedidos pelo Banco Mundial e 75 milhões partiram do Banco Interamericano de Desenvolvimento (Ribeiro, 2006, p. 302). Segundo Lara Resende (1982), "o Brasil foi, durante o período 196467, o quarto maior receptor mundial de ajuda da AID, atrás somente da Índia, do Paquistão e do Vietnã do Sul" (Lara Resende, 1982, p. 782-783).

Diante destas evidências, é indiscutível que o tratamento diferenciado dado pelos norte-americanos ao governo Castelo Branco foi fator decisivo no que concerne às diferenças no desempenho do PAEG e do Trienal. A pouca ajuda recebida pela missão de San Tiago Dantas de 1963 manteve a situação de estrangulamento externo e eliminou qualquer chance de sucesso do Plano Trienal.

Por sua vez, a ajuda generosa recebida pelo governo militar desde 1964 foi decisiva para aliviar a pressão no balanço de pagamentos, permitindo, com isso, que as políticas do PAEG pudessem ser implementadas em um ambiente muito mais favorável no que tange às contas externas. Em 1964, o balanço de pagamentos fechou praticamente em equilíbrio (déficit de US\$ 2 milhões), enquanto que em

${ }^{33}$ A facilidade com que os recursos eram obtidos fica patente no depoimento de Casimiro Ribeiro, membro da primeira diretoria do Banco Central do Brasil, sobre as negociações com o FMI no início do governo Castello Branco. Assim relatou Casimiro Ribeiro (1990): "Não foi difícil negociar com o FMI - eu fui o chefe da missão que negociou. Eles concordaram com o nosso plano. Não foi plano, como dizem que o FMI impôs um plano ao Brasil. Nosso plano foi aprovado. Bulhões e Roberto Campos não foram a Washington, como vão os ministros agora, toda hora, conversar para levar um 'não'. Eles não foram. Quem foi fui eu. Eu fui, em nome do governo: 'Vim aí fechar negócio'. Na hora de assinar, mandou-se o texto para o dr.Bulhões...”. (Ribeiro, 1990, p. 32-33) 
1965 registrou um superávit de U\$S 218 milhões, resultados que contrastam com os déficits de U\$S 37 milhões e U\$S 118 milhões registados em 1963 e 1962, respectivamente. ${ }^{34}$

\section{Conclusões}

O presente artigo discutiu as similaridades e diferenças entre as políticas de estabilização de curto prazo do Plano Trienal e do PAEG, bem como as razões que explicam os resultados distintos alcançados pelos dois planos. Do ponto de vista da análise comparativa das políticas de estabilização de curto prazo, mostrou-se que o Trienal e o PAEG possuíam semelhanças, dado que ambos viam a necessidade de uma inflação corretiva, propunham uma estratégia gradualista de combate à inflação e estabeleciam políticas monetárias e fiscais contracionistas. Todavia, havia também aspectos distintos entre os planos. Neste contexto, uma diferença foi o fato de o PAEG, diferentemente do Plano Trienal, ter introduzido a correção monetária. Outro ponto importante de distinção foram as políticas salariais adotadas pelos dois planos.

Observou-se que as políticas salariais tiveram um peso importante nos resultados alcançados pelos planos. $\mathrm{Na}$ época de Goulart viviase um momento de grande conflito distributivo e, neste contexto, o Plano Trienal não apresentou mecanismos para conter a espiral inflacionária. O governo de Castello Branco, oriundo do golpe militar de 1964, não possuía os mesmos dilemas. Desta forma, a equipe econômica que formulou o PAEG não teve constrangimentos em cortar a espiral inflacionária a partir do arrocho salarial.

Todavia, apesar do peso importante das questões internas, o cenário externo foi também decisivo para os resultados obtidos pelo Trienal e pelo PAEG. Ambos os planos foram formulados em um contexto de estrangulamento externo, de modo que o reescalonamento da divida externa era uma questão crucial. O governo Goulart encontrou enormes resistências dos norte-americanos, obtendo uma ajuda inexpressiva por parte deles. $\mathrm{O}$ fracasso da missão que foi a Washington em março de 1963 criou uma situação de asfixia nas contas externas

${ }^{34}$ Contudo, a ajuda obtida durante ogoverno Castello Branco teve contrapartidas. No caso, o Brasil adotou, ao menos no curto prazo, uma política externa mais alinhada com os Estados Unidos. 
que eliminava qualquer possibilidade de a economia voltar a crescer e, igualmente, de as pressões inflacionárias serem contidas. O governo Castello Branco, por outro lado, encontrou um clima bem mais amigável nas negociações internacionais, marcado por uma maior boa vontade com as demandas do Brasil. O resultado foram acordos que desafogaram as contas externas, criando um ambiente mais propício para o sucesso das políticas de estabilização e também para o crescimento econômico.

Em síntese, as experiências do Trienal e do PAEG mostram como os contextos interno e externo levaram ao fracasso do primeiro e a resultados muito melhores no que diz respeito ao segundo. A tumultuada conjuntura interna e a combinação de medidas de inflação corretiva sem regras de contenção salarial eliminaram as chances de êxito do Trienal no combate à inflação.

Ao mesmo tempo, a pouca ajuda externa - diferentemente do que ocorreu com o governo Castello Branco - estrangulou a capacidade de importar do governo Goulart, eliminando qualquer possibilidade de crescimento econômico. Assim, a impossibilidade de equacionar os problemas do conflito distributivo e do estrangulamento externo minou o intento do Trienal de conciliar estabilidade de preços com crescimento econômico. O PAEG, por sua vez, não padeceu destes problemas, pois resolveu o conflito distributivo com uma solução regressiva e atenuou a restrição externa com a boa vontade do governo norte-americano na concessão de empréstimos e reescalonamento das dívidas.

\section{Referências}

BASTOS, P.P.Z. O Plano Trienal e sua Economia Política. In: O Plano Trienal e o Ministério do Planejamento, Centro Celso Furtado, Rio de Janeiro: Contraponto, 2011.

CAMPOS, R. A Lanterna na Popa. Rio de Janeiro: Topbooks, 1994.

CARDOSO, F.H. Aspectos Políticos do Planejamento. In: LAFER, Betty Mindlin (org.). Planejamento no Brasil. São Paulo: Editora Perspectiva, 1970.

COLISTETE, R.P. Productivity, Wages and Labor Politics in Brazil, 1945-62. Journal of Economic History, vol.67, $\mathrm{N}^{\mathrm{o}} 1,2007$.

FONSECA, P.C.D. Legitimidade e Credibilidade: Impasses da Política Econômica do Governo Goulart. Estudos Econômicos, v.34, n.5, 2004.

FURTADO, C. Obra Autobiográfica de Celso Furtado. São Paulo: Paz e Terra, 1997. 
HERMANN, J. Reformas, Endividamento Externo e o "Milagre” Econômico (1964-73). In: GIAMBIAGI, F.; VILLELA, A.; CASTRO, L.B.; HERMANN, J.(org.). Economia Brasileira Contemporânea (1945-2004). Rio de Janeiro: Campus, 2004.

LARA RESENDE, A.. A Política Brasileira de Estabilização 1963/68. Pesquisa e Planejamento Econômico, vol. 12, n.3, 1982.

LARA RESENDE, A. Estabilização e Reforma: 1964-1967. In: ABREU, M.P. A Ordem do Progresso. Rio de Janeiro: Campus, 1990.

LOUREIRO, F.P. A “Última Chance”; o governo Kennedy e o Plano Trienal. Anais do IX Congresso Brasileiro de História Econômica e 10a Conferência Internacional de História de Empresas, Curitiba, 07-09 de setembro, 2011.

MACEDO, R.B.M. Plano Trienal de Desenvolvimento Econômico e Social (1963-1965). In: LAFER, B. M. (org.). Planejamento no Brasil. São Paulo: Editora Perspectiva, 1970.

MALAN, P.S. Relações Econômicas Internacionais do Brasil (1945-1964). In: FAUSTO, Boris (dir.). História Geral da Civilização Brasileira: Tomo III-O Brasil Republicano-Economia e Cultura (1930-1964). São Paulo: DIFEL, 1984.

MELO, H.; BASTOS, C.P.; ARAÚJO, V.L. A Política Macroeconômica e o Reformismo Social: impasses de um governo sitiado. In: FERREIRA, Maria de Moraes (coor.). João Goulart: entre a História e memória. Rio de Janeiro: FGV, 2008.

MONIZ BANDEIRA, L. A. O Governo João Goulart: as lutas sociais no Brasil 1961-1964. São Paulo: Editora UNESP, 2010.

PAEG - Programa de Ação Econômica do Governo 1964-1966. Documentos EPEA - nº 1, Rio de Janeiro, 1964.

PLANO TRIENAL DE DESENVOLVIMENTO ECONÔMICO E SOCIAL 1963- 65. In: O Plano Trienal e o Ministério do Planejamento, Centro Celso Furtado, Rio de Janeiro: Contraponto, 2011.

RIBEIRO, Casimiro Antonio. Casimiro Ribeiro II-depoimento 1989. Rio de Janeiro: CPDOC, Banco Central, 1990. 97p.dat.

RIBEIRO, R.A. A Aliança para o Progresso e as Relações Brasil- Estados Unidos. Tese de Doutorado, Departamento de Ciência Política do Instituto de Filosofia e Ciências Humanas - Universidade Estadual de Campinas (Unicamp), 2006.

SIMONSEN, M.H. Inflação: Gradualismox Tratamento de Choque. Rio de Janeiro: Apec Editora, 1970.

SIMONSEN, M.H. A Politica Anti-inflacionária. In: SIMONSEN, M.H.; CAMPOS, R.O. A Nova Economia Brasileira. Rio de Janeiro: José Olympio, 1974.

SKIDMORE, T. Brasil: de Getúlio a Castelo. São Paulo: Paz e Terra, 1992.

SOCHACZEWSKI, A.C. Desenvolvimento econômico e financeiro do Brasil: 1952-1968. São Paulo: Trajetória Cultural, 1993.

SOLA, L. Idéias Econômicas, Decisões Políticas. São Paulo: Edusp, 1998. 